to provide incontrovertible evidence that in native nucleohistone the molecules of nucleohistone are in some regularly folded configuration with the DNA molecules inclined to the fibre axis. Stretching destroys regular folding and aligns the DNA molecules along the fibre axis. No increase in the spacing of the low angle rings is observed on stretching; instead the rings are replaced by diffuse scatter: this shows that the folded structure does not stretch uniformly but breaks up and becomes irregular on stretching. The regular folding re-forms when the specimen is wetted and relaxed. The super-helical model is an obvious choice for the folded structure. The stretching experiments are entirely consistent with a super-helical model but do not eliminate other types of fold in which the DNA molecules are inclined to the length of the nucleohistone molecule.

We thank Professor Sir John Randall for facilities, Mrs Rowena Hope and Mr Z. Gabor for assistance, and Dr H. G. Davies for discussion. J. F. P. acknowledges receipt of a Medical Research Council scholarship.

J. F. PARDON*

M. H. F. WILKINS

MRC Biophysics Research Unit,

King's College,

University of London.

Department of Biophysies,

King's College,

University of London.

Received July 4, 1967.

* Present address: Searle Research Laboratories, Lane End Road, High Wycombe, Buckinghamshire.

${ }^{3}$ Stedman, E., and Stedman, E., Phil. Trans. Roy. Soc., B, 235, 565 (1951).

${ }^{2}$ In The Nucleohistones (edit. by Bonner and 'Ts'o) (Holden-Day Inc., 1964).

${ }^{3}$ Wilkins, M. H. F., Zubay, G., and Wilson, H. R., J. Mol. Biol., 1, 179 (1959). 'Bayley, P. M., Preston, B. N., and Peacocke, A. R., Biochim. Biophys.
Acta, 66, 943 (1962).

'Gianonni, R., and Peacocke, A. R., Biochim. Biophys. Acta, 68, 157 (1963).

${ }^{6}$ DuPraw, E. J., Nature, 206, 338 (1965).

'Davies, H. G., Nature, 214, 208 (1967).

${ }^{8}$ Ris, H., J. Cell Biol., 31, 134A (1966).

${ }^{9}$ Wilkins, M. H. F., and Zubay, G., J. Mol. Biol., 7, 756 (1963).

${ }^{10}$ Wilkins, M. H. F., Contribution to Gordon Conference (1964).

${ }^{11}$ Pardon, J., thesis, Univ. London (1966).

${ }^{12}$ Limzzati, V., and Nicolaieff, A., J. Mol. Biol., 1, 127 (1959).

${ }^{13}$ Lu»zati, V., and Nicolaieff, A., J. Mol. Biol., ry, 142 (1963).

\section{Attempt to locate the $\alpha$-Helical Segments of Ribonuclease}

IN recent communications concerning the tertiary structure of ribonuclease two very different spaco models of this molecule were presented ${ }^{1,2}$. I wish to point out that, in circumstances such as these, a choice can be made between alternative structures or details of structures by a method based on a statistical matching of a given sequence of amino-acids with the sequences of proteins of known tertiary structure ${ }^{3}$. This method has been refined (my unpublished work) so that for every aminoacid position along the chain which is analysed the probability of that amino-acid belonging to an $\alpha$-helical segment can be calculated.

This method seems to give results which agree with $\mathrm{X}$-ray data in the case of the hen egg-lysozyme ${ }^{4,5}$, but still more controls are required before the goneral validity of the method can be tested.

The $\alpha$-helical segments of ribonuclease, according to Kartha et al. ${ }^{1}$, should be located in the regions 5-12, $28-35$ and $51-58$ of the ehain, but by statistical analysis I have obtained high probability figures for the residues 1-9, 14-23 and 47-59 (see Fig. 1).

Because of the difficulties and uncertainties involved in the determination of the tertiary structure of proteins

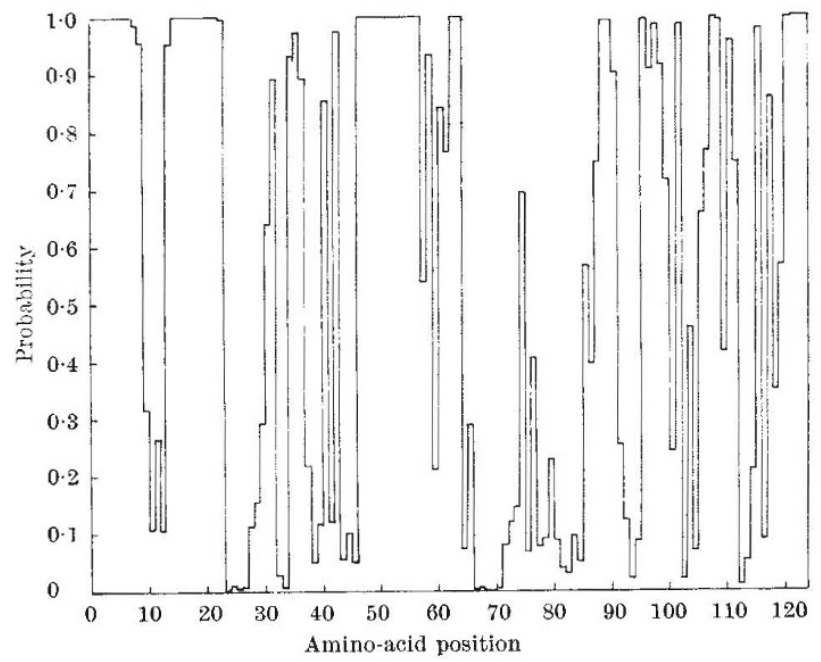

Fig. 1. Diagram showing the helical probability of the amino-acids of the ribonuclease. The abscissa shows the position on the chain from the $N$ - to the $C$-terminal, and the ordinate shows the probability of the residue being in $\alpha$-helical conformation. Note the strong signals in the regions 1-9, 14-23 and 47-59. The last stretch overlaps comfirst one overlaps only partially. There is no agreement for the second stretch.

I hope that this technique will be of some use in this kind of problem.

Department of Pharmacology,

P. F. Periti

University of Camerino,

Camerino.

Received March 31; revised June 29, 1967.

${ }^{1}$ Kartha, G., Bello, J., and Harker, D., Nature, 213, 862 (1967).

Avey, H. P., Boles, M. O., Carlisle, C. H., Evans, S. A., Morris, S. J., eriti, P. F., Quagliarotti, G., and Tiquori, A. M., J. Mol. Biol., (1967).

- Blake, C. C. F., Koenig, D. F., Mair, G. A., North, A. C. T., Phillips, D. C., and Sarma, V. R., Nature, 206, 757 (1965).

shillips, D. C., Sci. Amer., 215, 78 (1966).

\section{Cross-linking of Gelatine by Dehydration}

THE contribution of water to the stability of macromolecular struetures of biological origin is often difficult to assess. Besides its intrinsic theoretical interest ${ }^{1,2}$, this problem is of great practical importance in studies concerned with the preparation of single crystals of proteins $^{3}$ and nucleic acids from an aqueous mother liquor as well as in studies of such macromolecules in non-aqueous solvents ${ }^{4}$. For these reasons we believe that the detailed study of physicochemical changes which accompany the excessive dehydration of proteins and nucleic acids might be of considerable value. In this communication, we wish to report evidence that gelatine becomes covalently cross-linked when the water content falls below about $0 \cdot 2 \mathrm{~g} / 100 \mathrm{~g}$ protein.

Ossein gelatine having a weight-average molecular weight of about 300,000 was used in this work. The preparative procedure leading to this grade has been reported ${ }^{5}$ and a number of dilute solution properties of this gelatine have been determined ${ }^{5,6}$. The glass transition. temperature as well as the viscoelastic properties of films: prepared from this grado of gelatine have also been reported $^{5,7}$. We intend to show, however, that the observed behaviour of excessively dehydrated gelatine is apparently independent of source or preparative treatment.

The moisture content of gelatine samples was routinely determined using a modification of the procedure recom. mended by Eastoe and Courts ${ }^{8}$. The determination started with atmospheric oven drying at $105^{\circ} \pm 1^{\circ} \mathrm{C}$ for $24 \mathrm{~h}$ and was followed by evacuation under a pressure of 